\title{
CARACTERIZAÇÃO MINERALÓGICA, POTENCIAL DE RESERVA E SUSTENTABILIDADE AGRÍCOLA DE ALGUNS SÍTIOS FLORESTAIS DE EUCALIPTO DA REGIÃO DO VALE DO RIO DOCE (MG) ${ }^{(1)}$
}

\author{
A. REATTO( ${ }^{(2)}$, M. P. F. FONTES( ${ }^{(3)}$, V. H. ALVAREZ V. ${ }^{(3)}$, \\ M. RESENDE ${ }^{(3)}$, J . C. KE ${ }^{(3)}$ \& L. M. $\operatorname{COSTA}^{(3)}$
}

\begin{abstract}
RESUMO
Foram estudados alguns solos da região do Vale do Rio Doce (MG) em 1991, nos municípios de I patinga, Nova Era e Guanhães, provenientes de áreas de reflorestamento de Eucal yptus grandis. Selecionaram-se oito sítios florestais com solos de diferentes classes taxonômicas, e uma detalhada caracterização mineralógica e avaliação do potencial de reserva de nutrientes foram desenvolvidas. Os solos estudados foram mineralogicamente classificados como: caulinítico não-sesquioxídicos (2 e 5); caulinítico-sesquioxídico (1); gibbsíticosesquioxídicos (4, 6 e 7); hematítico (3) e gibbsítico (8). Os principais argilominerais e óxidos de ferro e alumínio presentes nesses solos são caulinita, gibbsita, hematita, goethita e maghemita. A reserva mineral de médio a longo prazo para potássio é praticamente inexistente, estando presente, embora com baixa magnitude, nos solos 2 e 5, na forma de micas e feldspatos. As relações Ca-trocável/Ca-total e Mg-trocável/Mg-total exprimem baixa capacidade de reposição desses nutrientes nos solos estudados. Sugere-se a adi ção de nutrientes de acordo com os níveis críticos exigidos na implantação e manutenção do ciclo do eucalipto, em virtude da ausência de sustentabilidade desses sítios florestais em termos de reserva de nutrientes a curto, médio e longo prazos.
\end{abstract}

Termos de indexação: mineralogia, potencial de reserva, Eucalyptus grandis, sustentabilidade agrícola.

\footnotetext{
(1) Parte da Tese de Mestrado do primeiro autor, apresentada ao Departamento de Sol os da Universidade Federal de Viçosa - UFV, Viçosa (MG). Recebido para publicação em agosto de 1996 e aprovado em fevereiro de 1998.

(2) Pesquisadora da EMBRAPA - Centro de Pesquisa Agropecuária dos Cerrados. Caixa Postal 08223, CEP $73301-970$ Planaltina (DF).

(3) Professor do Departamento de Solos, Universidade Federal de Viçosa. CEP. 36571-000 Viçosa (MG). Bolsista do CNPq.
} 


\title{
SUMMARY:MINERALOGICAL CHARACTERIZATION, NUTRIENT POTENTIAL RESERVE AND AGRICULTURAL SUSTAINABILITY OF SEVERAL FOREST SITES OF EUCALYPT FROM VALE DO RIO DOCE REGION (MG)
}

\begin{abstract}
Soils from the Vale do Rio Doce region in I patinga, Nova Era e Guanhães counties, State of Minas Gerais, Brazil, under reforestation with Eucalyptus grandis, were studied. Eight forest sites with soils from different taxonomic classes were selected and detailed mineralogical characterization and evaluation for nutrient reservepotential wereconducted in 1991. Thesoils studied were mineral ogically classified as: Kaol initic-non sesqui oxidic (2 and 5); kaol initic-sesquioxidic (1); gi bbsitic-sesquioxidic (4, 6 and 7); hematitic (3) and gibbsitic (8). The main silicate clay minerals and Fe and Al oxides found were kaolinite, goethite, hematite, gibbsite and maghemite The medium and long term mineral reserve of potassium is practically nonexistent, except for soils 2 and 5 , which present small amounts of micas and feldspars. The ratios of exchangeable total $\mathrm{Ca}$ and $\mathrm{Mg}$ demonstratea reduced capacity to replenish these nutrients. The addition of fertilizer nutrients according to the critical level to establish and maintain theeucalypt lifecycl eis suggested, taking into account the non-sustainability of these forest sites, as far as short, medium and long term nutrient reserves are concerned.
\end{abstract}

Index terms: mineralogy, reserve potential, Eucalyptus grandis, agricul tural sustainabi lity.

\section{NTRODUÇÃO}

O estudo da mineralogia dos solos é de grande valor, quando se trata de estudar o potencial de fertilidade e o comportamento físico-químico dos sol os. Nos mais intemperizados como os L atossolos, a influência das rochas não é tão marcante quanto nos solos mais jovens, como Podzólicos e, principalmente, Cambissolos, onde a influência do material de origem ainda se faz sentir de modo bastante intenso. Dessa forma, apesar de o conhecimento da mineralogia da rocha constituir grande subsídio ao estudo global do solo, quando a produção vegetal é o objeto final, a mineralogia da rocha deve ser complementada por um estudo aprofundado da mineralogia do solo. Nessa linha de pensamento, é importante se fazer uma completa identificação dos minerais primários e secundários presentes no perfil do solo.

Os minerais primários podem indicar a reserva mineral, ou seja, a capacidade de ser o solo fonte direta de nutrientes para as plantas. Costa (1979) sugere dividir a reserva mineral dos solos em: (a) de curto prazo, constituída por minerais primários facilmenteintemperizáveis, como olivina, piroxênios, anfibólios, biotita e mesmo minerais félsicos, como feldspatos K, muscovita, etc, em tamanho da fração silte; (b) de médio prazo, formada por minerais primários facilmente intemperizáveis, em tamanho da fração areia, e (c) de longo prazo, composta de minerais, como fel dspatos K, muscovita e outros de intemperização difícil, em tamanho da fração areia.

Os minerais secundários ocorrem no solo por síntese de produtos resultantes do intemperismo de minerais primários esão os constituintes principais da fração argila dos solos, relacionados com os fenômenos de lixiviação de nutrientes, adsorção de P, fixação de K, etc. (Costa, 1979).

No Brasil, os problemas nutricionais em plantações de eucal ipto se intensificaram à medida que os plantios se estenderam para solos mais pobres. Um programa operacional de adubação eficiente deve levar em consideração fatores como clima-solo-planta-fertilizante. I sso se concretiza na identificação de locais com potencial de reserva de nutrientes; na sel eção das fontes de nutrientes, com base nas características do solo e do dima e na forma, modo e época de aplicação do fertilizante, propiciando retorno econômico satisfatório. O potencial de reserva de nutrientes dos sol os na forma de minerais primários esecundários pode contribuir com a ciclagem desses nutrientes em eucalipto, tornando seu manejo nutricional sustentável.

Este estudo objetivou a caracterização mineralógica e a avaliação do potencial de reserva de nutrientes das frações areia, silte e argila de alguns solos sob reflorestamento de Eucalyptus grandis, na região do Vale do Rio Doce (MG), visando avaliar a sustentabilidade agrícola.

\section{MATERIAL E MÉTODOS}

A área em estudo localiza-se na parte centro-sul da região Sudeste do Brasil, no estado de Minas Gerais, região do Vale do Rio Doce, nos municípios de N ova Era, I patinga e Guanhães (Figura 1). 


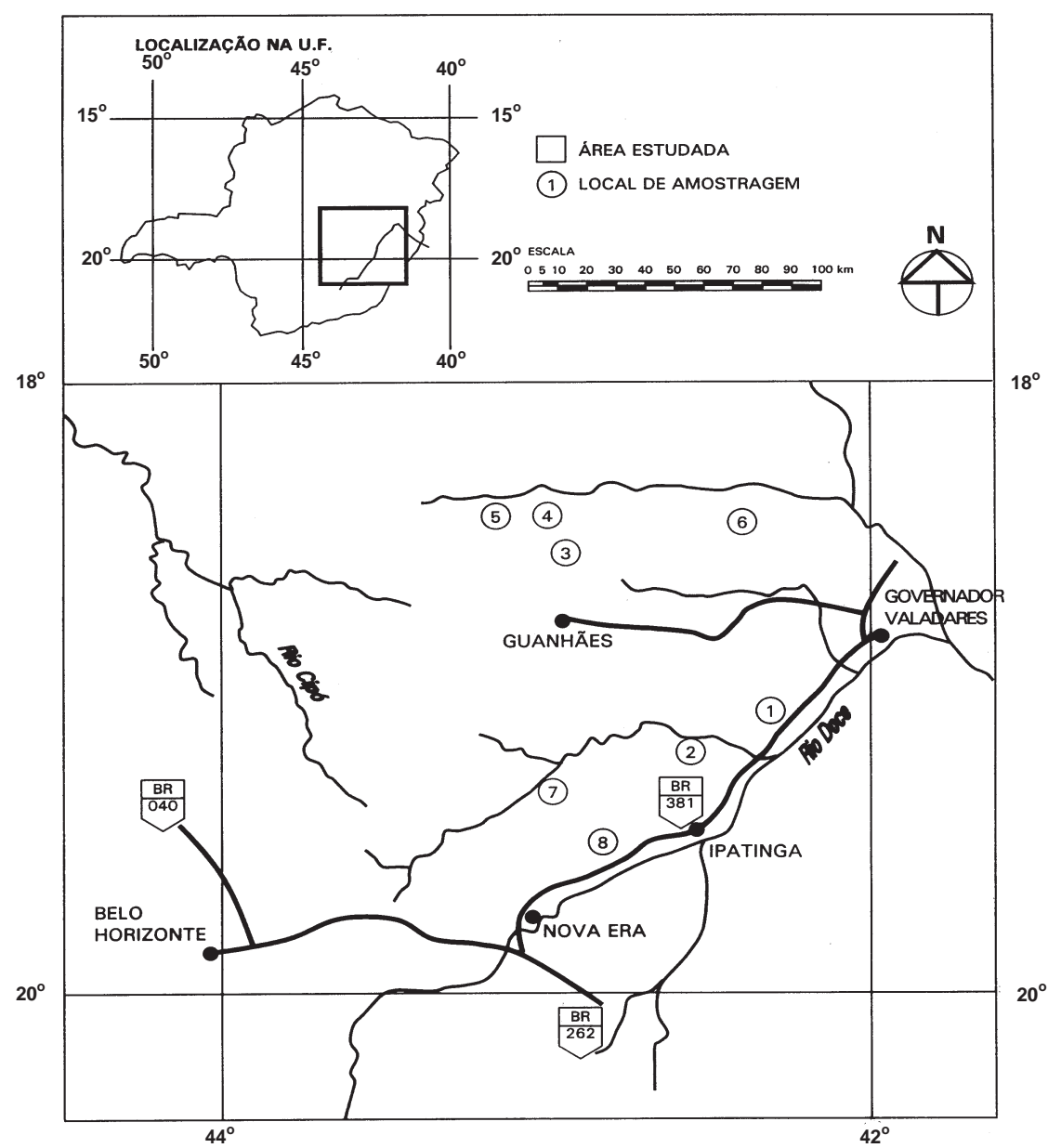

Figura 1. Mapa de situação na Unidade Federativa (U.F.) e localização dos solos estudados.

O clima predominante na região de interesse é Cwa, de acordo com a classificação de Köppen. A precipitação média anual é de 1.300 a $1.500 \mathrm{~mm}$ (Nova Era e Guanhães) e 1.000 a 1.200 mm (I patinga). O déficit hídrico é de 10 a $30 \mathrm{~mm}$, inverno com dois a quatro meses secos (Nova Era e Guanhães); 30 a 40 mm, inverno com 4 a 5 meses secos (I patinga). A evapotranspiração potencial anual é de 800 a $850 \mathrm{~mm}$ (Nova Era e Guanhães), 950 a $1.200 \mathrm{~mm}$ (I patinga), segundo Golfari (1975) e Cuzinato (1987), citados por Fabres et al. (1987).

Originalmente, a vegetação era formada, predominantemente, por florestas subperenifólia e subcaducifólia. Com a intervenção humana, a vegetação original cedeu lugar a formações secundárias, caracterizadas por árvores de pequeno porte e com acentuada heterogeneidade.

Foram escolhidos oito sítios florestais com povoamentos de Eucalyptus grandis e sel ecionados solos de diferentes classes taxonômicas, discriminados na figura 1 e quadro 1.

Os perfis foram descritos, segundo Lemos \& Santos (1982), na posição relativa ao ponto de inflexão da encosta. Em média, foram coletados e analisados quatro horizontes por perfil.

Procedeu-se à separação das frações conforme Santos (1993). Pesaram-se 20 a $30 \mathrm{~g}$ de solo (TFSA), correspondentes a 5 a $10 \mathrm{~g}$ de argila, estimados com base na anál ise granulométrica (E MBRAPA, 1979). Da fração areia, separaram-se os minerais leves e pesados por densidade (EMBRAPA, 1979), seguida de identificação e caracterização das espécies minerais na lupa. Para os minerais pesados, foi feita também a separação por ação magnética (EMBRAPA, 1979). Amostras das frações silte e argila foram distribuídas sobre vidro plano (por esfregaço) eanal isadas por difratometria de raios $X$, no intervalo de 4 - a 40 을 $2 \theta$, em aparelho Rigaku, sistema Geigerflex II, equipado com tubo de Cu e filtro deNi (J ackson,1979; Whittig \& Allardice, 1986).

Para a semiquantificação das espécies minerais na fração silte, utilizaram-se como subsídios os dados de ataque sulfúrico, alocação e difratogramas de raios X da fração argila. Maiores informações sobre o método para a semiquantificação da fração silte podem ser obtidas em Santos (1993). Paralelamente, 
Quadro 1. Classificação dos solos em estudo localizados em três municípios de Minas Gerais, sua respectiva mineralogia e litoestratigrafia

\begin{tabular}{|c|c|c|c|c|}
\hline Solo & Local & Classificação & Material de origem ${ }^{(1)}$ & Litoestratigrafia $^{(1)}$ \\
\hline 1 e 2 & I patinga & $\begin{array}{l}\text { Latossolo Vermel ho-Amarelo } \\
\text { álico textura argilosa e } \\
\text { Podzólico Vermel ho-Amarelo } \\
\text { distrófico textura argil osa }\end{array}$ & $\begin{array}{l}\text { Gnaisses de composição ácida } \\
\text { (granítica, granodiorítica e } \\
\text { monzonítica); gnaisses de } \\
\text { composição intermediária } \\
\text { (diorítica e tonalítica) }\end{array}$ & $\begin{array}{l}\text { Pré-Cambriano Indiviso, } \\
\text { Embasamento granito gnáissico }\end{array}$ \\
\hline 3 e 4 & Guanhães & $\begin{array}{l}\text { Latossolo F errífero câmbico } \\
\text { álico textura franco argilo } \\
\text { arenosa e Latossolo Vermelho- } \\
\text { E scuro ál ico textura argilosa }\end{array}$ & $\begin{array}{l}\text { I tabirito (quartzo, óxidos de } \\
\text { ferro - hematita e magnetita) }\end{array}$ & $\begin{array}{l}\text { Proterozóico Inferior, Super Grupo } \\
\text { Minas (Série M inas), Grupo I tabira } \\
\text { Médio }\end{array}$ \\
\hline 5 e 6 & Guanhães & $\begin{array}{l}\text { L atossolo Vermel ho-E scuro } \\
\text { câmbico áli co textura muito } \\
\text { argilosa e Latossolo Vermel ho- } \\
\text { E scuro ál ico textura argil losa }\end{array}$ & $\begin{array}{l}\text { Quartzito mi cáceo (quartzo e } \\
\text { muscovita) }\end{array}$ & $\begin{array}{l}\text { Proterozóico Inferior, Super Grupo } \\
\text { Minas (Série Minas), Grupo Caraça } \\
\text { Inferior }\end{array}$ \\
\hline 7 e 8 & Nova Era & $\begin{array}{l}\text { Latossolo Vermel ho-Amarelo } \\
\text { álico textura franco argil osa e } \\
\text { L atossolo Vermel ho-Amarelo } \\
\text { Podzólico álico textura } \\
\text { argilosa }\end{array}$ & $\begin{array}{l}\text { Batólitos de granito e } \\
\text { granodiorito }\end{array}$ & $\begin{array}{l}\text { Pré-Cambriano Indiviso, Rochas } \\
\text { İ gneas Ácidas }\end{array}$ \\
\hline
\end{tabular}

(1) FONTE: BRASIL $(1970,1983)$.

calculou-sea porcentagem de cada mineral da fração argila por alocação, a partir dos dados de ataque sulfúrico (Resende et al., 1987), excluindo-se o teor de maghemita, estimado por medidas de magnetização (Resende et al., 1986). Determinou-se, também, a magnetização da fraçãoargila, usando-seuma balança analítica, emqueum dos pratos metálicosfoi substituído por um de polietileno (Resende \& Santana, 1988).

Foramfeitas caracterizações químicas nas amostras, determinando-se: $\mathrm{pH}_{\mathrm{H}_{2} \mathrm{O}} ; \mathrm{pH}_{\mathrm{KCl}} ; \mathrm{K}$ trocável (extrator Mehlich- $1, \mathrm{HCl}$ 0,05 mol L-1 $+\mathrm{H}_{2} \mathrm{SO}_{4}$ 0,0125 mol L-1); $\mathrm{Ca}, \mathrm{Mg}$, Al trocáveis (extrator $\mathrm{KCl}-1$ mol L-1); $\mathrm{H}+\mathrm{Al}$ extraível (método potenciométrico do SMP - Raij et al., 1987), e K, Ca e Mg totais (ataque fluorídrico). Os teores dos elementos Fe, Al, P, Ti e Si foram determinados por ataque sulfúrico (Vettori, 1969) e expressos na forma de óxidos.

Avaliou-se o crescimento do eucalipto por meio do cál culo do I ncremento Médio Anual (IMA) ( $\mathrm{m}^{3} \mathrm{ha}^{-1}$ ano-1), para o qual foram selecionadas 100 árvores de Eucalyptus grandis em cada sítiofl orestal, sendo mensuradas a altura e a circunferência à altura do peito (CAP). O volume sólido $\left(\mathrm{V}, \mathrm{m}^{3}\right)$ de madeira com casca foi determinado por meio da fórmula( 4): $\log V=-4,26+1,87 \log D+0,97 \log H$, sendo: $\mathrm{D}=$ diâmetro à al tura do peito $(\mathrm{cm}) ; \mathrm{H}=$ =al tura (m) $\left(R^{2}=0,99\right)$. A partir dos dados do volume sólido de madeira para cada árvore do sítio florestal, calculou-se o volume médio e multiplicou-se pela população de plantas (1.500 plantas ha-1), já descontadas as falhas (10\%). O val or resultante foi dividido pela idadedecada povoamentoe encontrou-seol MA. (4) Fabres, A.S, CENIBRA (Celulose Nipo-Brasileira), comu-
nicação pessoal.

\section{RESULTADOS E DISCUSSÃO}

\section{Mineralogia da fração areia}

A caracterização mineralógica da fração areia (Quadros 2 e 3) mostrou predomínio dos minerais leves, grãos de quartzo em quase a sua totalidade, para a maioria dos solos, exceto para os sol os 3 e 4, sobressaindo-se o sol o 3 com maior porcentagem de minerais pesados $\left(\mathrm{d}>2,97 \mathrm{~g} \mathrm{~cm}^{-3}\right)$, por estarem associados ao Grupo I tabira, composto de itabirito, rocha metamórfica constituída pela alternância de bandas de quartzo e de óxidos de ferro (hematita e magnetita). Nos solos 3 e 4, destacam-se na fração pesada minerais ultra-estáveis, como o rutilo, e minerais opacos, representados pela hematita e concreções ferruginosas.

O grupo de menor expressão é o dos minerais micáceos, presentes nos solos 2 e 5, representados pelos minerais leves. A presença desses minerais pode estar ligada à classe desses solos em estudo, Podzólico e Latossolo câmbico, solos menos intemperizados que os Latossolos. Cabe, ainda, ressaltar que o sol o 5, associado ao Grupo Caraça, é constituído especialmente de quartzitos micáceos (Quadro 3). A presença de minerais primários na fraçãoareia, como feldspatos potássicos emuscovitas, podecontribuir para formas trocáveis enão-trocáveis de K no solo.

\section{Mineralogia da fração silte}

Na fração silte, os minerais que, de maneira geral, ocorrem em todos os perfis são goethita, caulinita, gibbsita e hematita (Quadro 4). A goethita é o único mineral presente em todos os horizontes, 
Quadro 2. Minerais leves e pesados da fração areia

\begin{tabular}{|c|c|c|c|c|}
\hline \multirow{2}{*}{ Solo } & \multirow{2}{*}{ Horizonte } & \multirow{2}{*}{ Leves } & \multicolumn{2}{|c|}{ Pesados } \\
\hline & & & Magnéticos & Não-magnéticos \\
\hline & & $\longrightarrow$ & $\mathrm{g} \mathrm{kg}^{-1}$ & - \\
\hline 1 & $\begin{array}{l}\text { A } \\
\text { B w } \\
\text { B C } \\
\text { C }-4 m\end{array}$ & $\begin{array}{l}992,5 \\
993,5 \\
964,5 \\
992,5\end{array}$ & $\begin{array}{r}4,5 \\
4,5 \\
34,0 \\
5,0\end{array}$ & $\begin{array}{l}3,0 \\
2,0 \\
1,5 \\
2,5\end{array}$ \\
\hline 2 & $\begin{array}{l}\text { A } \\
\text { Bt } \\
\text { BC } \\
C-4 m\end{array}$ & $\begin{array}{l}962,0 \\
981,5 \\
978,5 \\
981,5\end{array}$ & $\begin{array}{r}30,0 \\
7,0 \\
6,5 \\
3,5\end{array}$ & $\begin{array}{r}8,0 \\
11,5 \\
15,0 \\
15,0\end{array}$ \\
\hline 3 & $\begin{array}{l}\text { A } \\
B \text { w } \\
C \\
C R\end{array}$ & $\begin{array}{l}201,0 \\
158,2 \\
185,5 \\
187,0\end{array}$ & $\begin{array}{r}84,5 \\
508,5 \\
563,0 \\
479,0\end{array}$ & $\begin{array}{l}714,5 \\
333,3 \\
251,5 \\
334,0\end{array}$ \\
\hline 4 & $\begin{array}{l}\text { A } \\
\text { B w } \\
\text { B C } \\
\text { C }-4 m\end{array}$ & $\begin{array}{l}646,0 \\
898,5 \\
865,5 \\
891,0\end{array}$ & $\begin{array}{r}168,0 \\
82,5 \\
121,0 \\
95,0\end{array}$ & $\begin{array}{r}186,0 \\
19,0 \\
13,5 \\
14,0\end{array}$ \\
\hline 5 & $\begin{array}{l}\text { A } \\
\text { B w } \\
\text { C } \\
\text { C }-4 m\end{array}$ & $\begin{array}{l}972,5 \\
947,5 \\
876,0 \\
974,0\end{array}$ & $\begin{array}{l}22,0 \\
45,0 \\
91,0 \\
19,0\end{array}$ & $\begin{array}{r}5,5 \\
7,5 \\
33,0 \\
7,0\end{array}$ \\
\hline 6 & $\begin{array}{l}\text { A } \\
\text { B w } \\
\text { CB } \\
\text { C }-4 m\end{array}$ & $\begin{array}{l}936,0 \\
929,0 \\
914,0 \\
944,5\end{array}$ & $\begin{array}{l}55,0 \\
66,0 \\
75,0 \\
51,0\end{array}$ & $\begin{array}{r}9,0 \\
6,0 \\
11,0 \\
4,5\end{array}$ \\
\hline 7 & $\begin{array}{l}\text { A } \\
B \text { w } \\
B / C \\
C-4 m\end{array}$ & $\begin{array}{l}900,0 \\
952,0 \\
967,0 \\
968,0\end{array}$ & $\begin{array}{r}95,5 \\
33,0 \\
20,5 \\
2,5\end{array}$ & $\begin{array}{r}4,5 \\
15,0 \\
12,5 \\
29,5\end{array}$ \\
\hline 8 & $\begin{array}{l}\text { A } \\
\text { B w } \\
\text { B C } \\
\text { C }-4 m\end{array}$ & $\begin{array}{l}898,0 \\
954,0 \\
943,5 \\
980,0\end{array}$ & $\begin{array}{r}92,5 \\
36,5 \\
51,5 \\
5,0\end{array}$ & $\begin{array}{r}9,5 \\
9,5 \\
5,0 \\
15,0\end{array}$ \\
\hline
\end{tabular}

confirmando sua ocorrência comum nos mais diferentes Latossolos, ainda que vermelhos. A ausência de argilas 2:1 e a presença comum de gibbsita em todos os solos indicam acentuada intemperização (ambiente de lixiviação intensa e drenagem desimpedida). Observa-se, também, que, no perfil 3, a hematita sobressai-se em relação aos outros perfis (Quadro 4), o que pode ser explicado pelo material de origem (Quadro 1).

\section{Mineralogia da fração argila}

$\mathrm{Na}$ fração argila, os minerais presentes são caulinita, maghemita, hematita, goethita e gi bbsita (Quadro 5 e Figuras 2 e 3). Observam-se, também, nos sol os 3 e 4, maiores porcentagens de hematita e maghemita atribuídas à intemperização do material de origem (itabirito) desses solos (Resende, 1976; Curi, 1983).

\section{Mineralogia geral}

Os valores limites para índices $\mathrm{Ki}$ e $\mathrm{Kr}$, apresentados por Resende \& Santana (1988), permitem inferir sobre o grau de intemperismo e aplicação desse critério aos Latossolos, resultando nos seguintes agrupamentos: L atossol os caul inítico não-sesquioxídicos, $\mathrm{Ki}>0,75$ e Kr $>0,75$; Latossolos caulinítico-sesquioxídicos, $\mathrm{Ki}>0,75$ e $\mathrm{Kr} \leq 0,75$ e Latossolos gibbsítico-sesquioxídicos, $\mathrm{Ki} \leq 0,75$ e $\mathrm{Kr}$ $\leq 0,75$. Deacordo com os val ores de Ki eKr (Quadro6), os sol os 2 e 5 foram classificados como cauliníticonão-sesquioxídicos; os solos 3, 4, 6, 7 e 8, como gibbsítico-sesquioxídicos, e o sol o 1, como cauliníticosesquioxídico.

Verifica-se que o trabal ho desses autores mostrou, considerando o critério de diferenciação da mineralogia dos solos, coerência, ao classificar os sol os 2 e 5 como caulinítico-não-sesquioxídicos, em que os difratogramas de raios $X$ da fração argila (Figuras 2 e 3) registram picos característicos de caulinita, sobrepondo-se aos picos dos sesquióxidos.

$\mathrm{Na}$ composição mineralógica da fração silte e argila, respectivamente (Quadros 4 e 5), a porcentagem de caulinita é maior que a soma das porcentagens dos sesquióxidos. Esse critério de classificação também foi coerente para o solo 1 , caulinítico-sesquioxídico, apresentando a porcentagem de caulinita proporcional ao somatório dos sesquióxidos (Quadros 4 e5). J á os sol os 4, 6 e 7, segundo o critério de dassificação, foram enquadrados como gibbsítico-sesquioxídicos, apesar de os difratogramas de raios X (Figuras 2 e 3) e da mineralogia das frações silte e argila (Quadros 4 e 5) revelarem a presença da caulinita de maneira significativa.

Os sol os 3 e 8 foram classificados como gi bbsíticosesquioxídicos. O critério de classificação utilizado para esses sol os não foi adequado por causa de suas características intrínsecas. O solo 3 é constituído da alternância de quartzito e óxidos de ferro, com predomínio de hematita constatada no di fratograma de raios $X$ da fração argila (Figura 2) e das frações silte e argila (Quadros 4 e 5, respectivamente). A classificação mineralógica apropriada seria solo hematítico. J á o sol o 8 mostra a maior concentração de óxidos na forma de gibbsita como verificado no difratograma de raios X (Figura 3 ), resultados de al ocação (Quadro 5) e porcentagem desse mineral na fração silte (Quadro 4), sendo sua melhor denominação sol o gibbsítico.

O avançado estádio de intemperismo dos solos estudados podeser observadono horizontediagnóstico, apresentando baixa capacidade de troca catiônica, variandoentre 24,4 e $48,5 \mathrm{mmol}_{c} \mathrm{dm}^{-3}$, baixa saturação por bases, variando entre 1 e $2 \%$, e alta porcentagem de saturação por alumínio, variando entre 68 e 94\%, à exceção do solo 2, que apresentou 21\% de saturação por bases e 42\% desaturação por al umínio (Quadro 7). 
Quadro 3. Composição mineralógica da fração areia

\begin{tabular}{|c|c|c|c|c|c|c|c|c|c|c|c|c|}
\hline \multirow{2}{*}{ Solo } & \multirow{2}{*}{ Horizonte } & \multicolumn{6}{|c|}{ Minerais leves } & \multicolumn{5}{|c|}{ Minerais pesados } \\
\hline & & Qz & cMn & $\mathbf{F p}$ & Sc & Mi & Ct & $\mathbf{R u}$ & Zc & Gd & cFe & $\mathbf{H m}$ \\
\hline & & 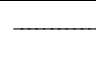 & & & & & $-\mathrm{g} \mathrm{kg}^{-1}$ & 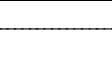 & - & 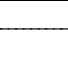 & 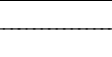 & 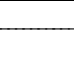 \\
\hline 1 & $\begin{array}{l}\text { A } \\
\text { Bw } \\
\text { BC } \\
\text { C-4m }\end{array}$ & $\begin{array}{l}428,7 \\
317,9 \\
308,9 \\
426,6\end{array}$ & & & & & $\begin{array}{r}0,60 \\
x\end{array}$ & $\begin{array}{l}0,60 \\
0,30 \\
0,24 \\
0,54\end{array}$ & 0,06 & & $\begin{array}{l}0,32 \\
0,16 \\
0,12 \\
0,27\end{array}$ & $\begin{array}{l}0,19 \\
0,16 \\
0,12 \\
0,27\end{array}$ \\
\hline 2 & $\begin{array}{l}\text { A } \\
\text { Bt } \\
\text { BC } \\
\text { C-4m }\end{array}$ & $\begin{array}{l}432,9 \\
233,6 \\
216,2 \\
270,9\end{array}$ & $\begin{array}{r}48,1 \\
27,5 \\
x \\
x\end{array}$ & $\begin{array}{r}13,7 \\
63,6 \\
158,0\end{array}$ & & & $\begin{array}{r}x \\
x \\
9,0\end{array}$ & $\begin{array}{l}1,60 \\
1,28 \\
1,56 \\
2,76\end{array}$ & $\begin{array}{l}x \\
x \\
x\end{array}$ & & $\begin{array}{l}1,20 \\
0,97 \\
0,17 \\
2,07\end{array}$ & $\begin{array}{l}1,20 \\
0,97 \\
0,17 \\
2,07\end{array}$ \\
\hline 3 & $\begin{array}{l}A \\
B w \\
C \\
C R\end{array}$ & $\begin{array}{l}78,4 \\
69,7 \\
79,8 \\
97,2\end{array}$ & & $x$ & $\begin{array}{l}x \\
x\end{array}$ & & $x$ & $\begin{array}{r}139,30 \\
73,26 \\
54,07 \\
69,47\end{array}$ & & & $\begin{array}{r}139,30 \\
73,26 \\
54,07 \\
69,47\end{array}$ & \\
\hline 4 & $\begin{array}{l}\text { A } \\
\text { Bw } \\
\text { BC } \\
C-4 m\end{array}$ & $\begin{array}{l}129,1 \\
179,7 \\
164,4 \\
151,5\end{array}$ & & & $\begin{array}{l}x \\
x \\
x\end{array}$ & & $\begin{array}{l}x \\
x \\
x \\
x\end{array}$ & $\begin{array}{r}18,6 \\
1,9 \\
2,56 \\
1,19\end{array}$ & $\begin{array}{l}x \\
x\end{array}$ & $x$ & $\begin{array}{r}9,3 \\
0,95 \\
1,28 \\
0,59\end{array}$ & $\begin{array}{l}9,30 \\
0,95 \\
1,28 \\
0,59\end{array}$ \\
\hline 5 & $\begin{array}{l}\text { A } \\
\text { Bw } \\
\text { C } \\
\text { C }-4 m\end{array}$ & $\begin{array}{r}308,0 \\
317,2 \\
173,4 \\
46,7\end{array}$ & & & $\begin{array}{l}24,5 \\
17,1\end{array}$ & $\begin{array}{r}17,5 \\
6,8 \\
115,6 \\
187,0\end{array}$ & & $\begin{array}{l}0,99 \\
1,35 \\
2,18 \\
0,34\end{array}$ & $\begin{array}{l}0,40 \\
0,40 \\
1,09 \\
0,08\end{array}$ & & $\begin{array}{l}0,59 \\
0,94 \\
4,35 \\
0,75\end{array}$ & \\
\hline 6 & $\begin{array}{l}\text { A } \\
\text { Bw } \\
\text { CB } \\
\text { C-4m }\end{array}$ & $\begin{array}{l}346,3 \\
260,1 \\
301,3 \\
234,5\end{array}$ & & & $\begin{array}{l}x \\
x \\
x\end{array}$ & & $\begin{array}{l}x \\
x \\
x\end{array}$ & $\begin{array}{l}0,16 \\
0,84 \\
1,54 \\
1,10\end{array}$ & $\begin{array}{l}0,66 \\
0,02 \\
0,08 \\
0,06\end{array}$ & & $\begin{array}{l}2,47 \\
0,81 \\
2,11 \\
1,51\end{array}$ & \\
\hline 7 & $\begin{array}{l}A \\
B w \\
B / C \\
C-4 m\end{array}$ & $\begin{array}{l}436,0 \\
333,2 \\
387,2 \\
193,6\end{array}$ & & 48,4 & $\begin{array}{l}x \\
x \\
x\end{array}$ & 242,0 & $\begin{array}{r}22,9 \\
6,6 \\
3,9\end{array}$ & $\begin{array}{r}1,15 \\
2,62 \\
2,00 \\
\times\end{array}$ & $\begin{array}{r}1,05 \\
0,50 \\
\times\end{array}$ & & $\begin{array}{r}1,15 \\
1,57 \\
2,75 \\
14,45\end{array}$ & \\
\hline 8 & $\begin{array}{l}A \\
\text { Bw } \\
B C \\
C-4 m\end{array}$ & $\begin{array}{l}468,7 \\
352,0 \\
385,4 \\
151,9\end{array}$ & & & & & $\begin{array}{r}52,1 \\
19,5 \\
20,3 \\
151,9\end{array}$ & $\begin{array}{l}2,75 \\
2,73 \\
1,07 \\
2,32\end{array}$ & $\begin{array}{l}2,48 \\
1,09 \\
1,07 \\
2,18\end{array}$ & & & \\
\hline
\end{tabular}

Qz - quartzo; cMn - concreções de manganês; Fp - feldspato; Sc - sericita; Mi - mica, mica intemperizada, muscovita; Ct - agregados de caulinita; Ru - rutilo; Zc - zirconita; Gd - granada; cFe - concreções de ferro; $\mathrm{Hm}$ - hematita; $\mathrm{x}$ - traços de minerais. Os locais em branco significam mineral não detectado.

O cálculo de minerais foi embasado na seguinte equação: minerais $=A \times B \times C$, em que
$A=\frac{\% \text { do mineral quantificado na lupa }}{100}$;
$B=\frac{\text { massa do mineral pesado ou leve }}{\text { massa da amostra }}$
$C=\%$ da fração areia(1)
(1) Foram usados os dados da análise granulométrica (EMBRAPA, 1979).

\section{Potencial de reserva para potássio}

Os valores de K-trocável e K-total foram consistentemente baixos na maioria dos solos. Para a maior parte dos solos estudados, observou-se um aumento noteor deK para as formas totais (extração com ácido fluorídrico) nos horizontes inferiores, fato também observado por Melo et al. (1995) em extrações de formas de $K$ mais estáveis com ácido sulfúrico. Esses autores explicam os menores val ores obtidos com ácido sulfúrico no horizonte superficial ao mais avançado estádio de intemperismo, em que parte dos minerais primários, eventualmente presentes nesses solos, já teria sido degradada, liberando o elemento para a sol ução, de ondeel e pode ser carreado por lixiviação para os horizontes inferiores ou ser absorvido pelas plantas.

Para as formas trocáveis de $\mathrm{K}$, os maiores teores foram encontrados no horizonte superficial para todos os solos. Esses valores elevados de K podem ser devidos à maior quantidade de serrapilheira no horizonte superficial, contribuindo com a conservação desse nutriente. Fonseca (1984) e Lima (1993), ao compararem solos com plantações de eucalipto, floresta natural e pastagem, observaram que, nesses ambientes, a camada superficial apresentou maiores teores de K, decrescendo do 
Quadro 4. Quantidade relativa das espécies minerais presentes na fração silte

\begin{tabular}{|c|c|c|c|c|c|}
\hline \multirow[t]{2}{*}{ Solo } & \multirow[t]{2}{*}{ Horizonte } & \multicolumn{4}{|c|}{$\begin{array}{c}\text { Minerais identificados por } \\
\text { difração raios } X\end{array}$} \\
\hline & & G t & H m & $\mathbf{C t}$ & G b \\
\hline 1 & $\begin{array}{l}\text { A } \\
\text { B w } \\
\text { B C } \\
\text { C }-4 m\end{array}$ & $\begin{array}{l}+ \\
+ \\
+ \\
+\end{array}$ & & $\begin{array}{l}++++ \\
+++++ \\
+++++ \\
+++++\end{array}$ & $\begin{array}{l}++++ \\
++++ \\
++++ \\
++\end{array}$ \\
\hline 2 & $\begin{array}{l}\text { A } \\
\text { B t } \\
\text { B C } \\
\text { C }-4 m\end{array}$ & $\begin{array}{l}+ \\
+ \\
+ \\
+\end{array}$ & $\begin{array}{l}+ \\
+ \\
+ \\
+\end{array}$ & $\begin{array}{l}+++++ \\
+++++ \\
+++++ \\
+++++\end{array}$ & $\begin{array}{l}+++ \\
+++ \\
++ \\
++++\end{array}$ \\
\hline 3 & $\begin{array}{l}\text { A } \\
B \text { w } \\
\text { C } \\
\text { C R }\end{array}$ & $\begin{array}{l}++ \\
++ \\
++ \\
++\end{array}$ & $\begin{array}{l}++++ \\
++++ \\
++++ \\
++++\end{array}$ & & $\begin{array}{l}+++ \\
+++ \\
+++ \\
+++\end{array}$ \\
\hline 4 & $\begin{array}{l}\text { A } \\
\text { B w } \\
\text { B C } \\
\text { C }-4 m\end{array}$ & $\begin{array}{l}+ \\
+ \\
+ \\
+\end{array}$ & $\begin{array}{l}+++ \\
+++ \\
++ \\
++\end{array}$ & $\begin{array}{l}++ \\
++++ \\
++++ \\
++++\end{array}$ & $\begin{array}{l}++++ \\
+++++ \\
++++ \\
++++\end{array}$ \\
\hline 5 & $\begin{array}{l}\text { A } \\
\text { B w } \\
\text { C } \\
\text { C }-4 m\end{array}$ & $\begin{array}{l}+ \\
+ \\
++ \\
+\end{array}$ & $\begin{array}{l}+ \\
+ \\
+ \\
+\end{array}$ & $\begin{array}{l}+++++ \\
+++++ \\
+++++ \\
+++++\end{array}$ & $\begin{array}{l}++ \\
++++ \\
++\end{array}$ \\
\hline 6 & $\begin{array}{l}\text { A } \\
\text { B w } \\
\text { C B } \\
\text { C }-4 m\end{array}$ & $\begin{array}{l}+ \\
+ \\
+ \\
+\end{array}$ & $\begin{array}{l}+ \\
+ \\
+ \\
+\end{array}$ & $\begin{array}{l}++++ \\
++++ \\
++++ \\
+++++\end{array}$ & $\begin{array}{l}++++ \\
++++ \\
+++ \\
+\end{array}$ \\
\hline 7 & $\begin{array}{l}\text { A } \\
B \text { w } \\
B / C \\
C-4 m\end{array}$ & $\begin{array}{l}+ \\
+ \\
+ \\
+\end{array}$ & & $\begin{array}{l}++++ \\
++++ \\
+++++ \\
++++++\end{array}$ & $\begin{array}{l}+++++ \\
++++ \\
++++ \\
+\end{array}$ \\
\hline 8 & $\begin{array}{l}\text { A } \\
\text { B w } \\
\text { B C } \\
C-4 m\end{array}$ & $\begin{array}{l}++ \\
++ \\
+ \\
+\end{array}$ & & $\begin{array}{l}+ \\
+ \\
+ \\
+\end{array}$ & $\begin{array}{l}+++++ \\
+++++ \\
+++++ \\
+++++\end{array}$ \\
\hline
\end{tabular}

Gt - goethita; H m - hematita; Ct - caulinita; Gb - gibbsita; $+1+1+$ maior 60\%; +1+40-60\%; +1+20-40\%; +10-20\%; +menor $10 \%$.

eucalipto (média de 27,2 t ha-1) para pastagem e mata nativa (11,6 t ha-1).

Os baixos valores da relação K-trocável/K-total constantes no quadro 8 revelam certo poder de recuperação para K-trocável, em todos os solos estudados. Segundo Boyer (1985), ainda não existem explicações satisfatórias sobre a procedência desse potássio. Costa( $\left.{ }^{5}\right)$ detectou - através do microscópio el etrônico de varredura, equipado com sistema de microanál ise por raios X (SEM-EDXRA) - picos deK, junto aos picos deAl eSi, em caul initas dohorizonteC de solos de Viçosa (MG), o que pode justificar os el evados val ores de K-total comparados aoK-trocável (Quadro 8), visto que os sol os em estudo continham caulinita em todos os horizontes (Quadro 5). Dados deSantos (1982) também já confirmavama presença de potássio em caulins brasileiros.

(5) Costa, L.M. - Professor Titular do Departamento de Solos da UFV, CEP 36571-000, Viçosa (MG).
Por outro lado, constatou-se que a dinâmica de reposição de K-trocável para as plantas deveria ser nula, ao avaliar-se o grau deretrogradação ou fixação de $\mathrm{K}$ em argilas do tipo 1:1 e óxidos de ferro e al umínio em comparação aos sol os que contêm ilita, montmorilonita e vermiculita, onde o potássio sai na forma solúvel do interior das lâminas da argila e vem preencher os sítios de troca (Boyer, 1985).

Os valores de K-trocável encontrados na maior parte dos sol os estudados satisfazem ao nível crítico de implantação para a cultura do eucal i pto em torno de $10 \mathrm{mg}$ de $\mathrm{K} \mathrm{dm}^{-3}$, mas não aos propostos para a manutenção - correspondentes aos I MAs 10, 20, 30, 40 e 50 os níveis críticos 30, 45, 60, 75 e 90 mg de $\mathrm{K} \mathrm{dm}^{-3}$ - de acordo com os val ores del MA observados nos sítios florestais em estudo (Quadro 8). Segundo proposições de Barros et al . (1990), os níveis críticos de potássio para eucalipto variam com a idade da planta ou com o crescimento do povoamento.

Quadro 5. Composição mineralógica da fração argila, determinada a partir de alocação

\begin{tabular}{|c|c|c|c|c|c|c|c|}
\hline Solo & Horizonte & $\mathbf{C t}$ & $M h^{(1)}$ & H m & Gt & G b & $\mathbf{T}$ \\
\hline & & \multicolumn{6}{|c|}{$\longrightarrow \mathrm{g} \mathrm{kg}^{-1} \longrightarrow$} \\
\hline 1 & $\begin{array}{l}\text { A } \\
\text { B w } \\
\text { BC } \\
C-4 m\end{array}$ & $\begin{array}{l}183,2 \\
255,0 \\
246,8 \\
353,9\end{array}$ & $\begin{array}{l}0,4 \\
0,4 \\
0,4 \\
0,3\end{array}$ & $\begin{array}{l}0 \\
0 \\
0 \\
0\end{array}$ & $\begin{array}{l}48,0 \\
50,8 \\
51,8 \\
30,5\end{array}$ & $\begin{array}{l}221,0 \\
239,0 \\
271,0 \\
171,0\end{array}$ & $\begin{array}{l}452,6 \\
545,2 \\
570,0 \\
555,7\end{array}$ \\
\hline 2 & $\begin{array}{l}\text { A } \\
B t \\
B C \\
C-4 m\end{array}$ & $\begin{array}{l}289,0 \\
365,5 \\
204,7 \\
279,5\end{array}$ & $\begin{array}{l}0,0 \\
0,8 \\
0,6 \\
0,0\end{array}$ & $\begin{array}{l}0 \\
0 \\
0 \\
0\end{array}$ & $\begin{array}{l}47,2 \\
62,4 \\
66,3 \\
36,1\end{array}$ & $\begin{array}{l}126,0 \\
185,0 \\
189,0 \\
217,0\end{array}$ & $\begin{array}{l}462,2 \\
613,7 \\
460,6 \\
532,6\end{array}$ \\
\hline 3 & $\begin{array}{l}A \\
B w \\
C \\
C R\end{array}$ & $\begin{array}{l}5,1 \\
4,7 \\
7,3 \\
1,7\end{array}$ & $\begin{array}{r}10,7 \\
6,5 \\
1,6 \\
1,0\end{array}$ & $\begin{array}{l}399,3 \\
486,6 \\
399,1 \\
305,0\end{array}$ & $\begin{array}{r}79,6 \\
88,1 \\
72,6 \\
180,6\end{array}$ & $\begin{array}{l}74,0 \\
63,3 \\
93,8 \\
65,3\end{array}$ & $\begin{array}{l}568,7 \\
649,2 \\
574,1 \\
553,6\end{array}$ \\
\hline 4 & $\begin{array}{l}\text { A } \\
\text { B w } \\
\text { BC } \\
\text { C- } 4 m\end{array}$ & $\begin{array}{r}286,8 \\
141,9 \\
169,8 \\
3,4\end{array}$ & $\begin{array}{l}2,6 \\
38\end{array}$ & $\begin{array}{l}69,3 \\
52,5 \\
73,7 \\
72,6\end{array}$ & $\begin{array}{l}34,7 \\
66,3 \\
42,5 \\
45,3\end{array}$ & $\begin{array}{l}205,3 \\
337,5 \\
343,9 \\
342,4\end{array}$ & $\begin{array}{l}598,7 \\
602,0 \\
633,2 \\
464,4\end{array}$ \\
\hline 5 & $\begin{array}{l}\text { A } \\
\text { B w } \\
\text { C } \\
\text { C-4m }\end{array}$ & $\begin{array}{l}362,3 \\
410,3 \\
429,2 \\
404,5\end{array}$ & 0,9 & $\begin{array}{l}0 \\
0 \\
0 \\
0\end{array}$ & $\begin{array}{r}66,3 \\
63,5 \\
102,1 \\
88,4\end{array}$ & $\begin{array}{l}30,0 \\
41,1 \\
65,0 \\
51,0\end{array}$ & $\begin{array}{l}459,5 \\
515,7 \\
597,1 \\
544,7\end{array}$ \\
\hline 6 & $\begin{array}{l}\text { A } \\
\text { B w } \\
\text { CB } \\
C-4 m\end{array}$ & $\begin{array}{r}132,0 \\
170,7 \\
99,3\end{array}$ & $\begin{array}{l}1,2 \\
0,8 \\
0,5 \\
0,8\end{array}$ & $\begin{array}{r}0 \\
0 \\
3,3 \\
41,9\end{array}$ & $\begin{array}{r}81,3 \\
96,0 \\
108,6 \\
39,8\end{array}$ & $\begin{array}{l}273,1 \\
279,5 \\
256,7 \\
199,2\end{array}$ & $\begin{array}{l}355,6 \\
508,3 \\
539,8 \\
381,0\end{array}$ \\
\hline 7 & $\begin{array}{l}\mathrm{A} \\
\mathrm{B} w \\
\mathrm{~B} / \mathrm{C} \\
\mathrm{C}-4 \mathrm{~m}\end{array}$ & $\begin{array}{l}194,4 \\
198,2 \\
213,7 \\
353,9\end{array}$ & $\begin{array}{l}0,5 \\
0,3 \\
0,4\end{array}$ & $\begin{array}{l}0 \\
0 \\
0 \\
0\end{array}$ & $\begin{array}{l}63,4 \\
76,8 \\
78,1 \\
64,8\end{array}$ & $\begin{array}{r}163,8 \\
271,4 \\
289,0 \\
45,9\end{array}$ & $\begin{array}{l}422,1 \\
546,7 \\
581,2 \\
464,6\end{array}$ \\
\hline 8 & $\begin{array}{l}\text { A } \\
\text { B w } \\
\text { BC } \\
C-4 m\end{array}$ & $\begin{array}{l}6,8 \\
3,4 \\
7,7 \\
4,7\end{array}$ & $\begin{array}{l}0,7 \\
0,4 \\
0,4 \\
0,0\end{array}$ & $\begin{array}{l}0 \\
0 \\
0 \\
0\end{array}$ & $\begin{array}{r}84,3 \\
108,9 \\
111,9 \\
131,0\end{array}$ & $\begin{array}{l}252,6 \\
369,7 \\
370,3 \\
511,7\end{array}$ & $\begin{array}{l}343,8 \\
482,4 \\
490,3 \\
647,4\end{array}$ \\
\hline
\end{tabular}

Ct - caulinita, Mh - maghemita, $\mathrm{Hm}$ - hematita, Gt - goethita, $\mathrm{Gb}$ - gibbsita, $\mathrm{T}$ - somatório dos minerais alocados.

(1) O teor de maghemita foi calculado a partir de magnetização. 


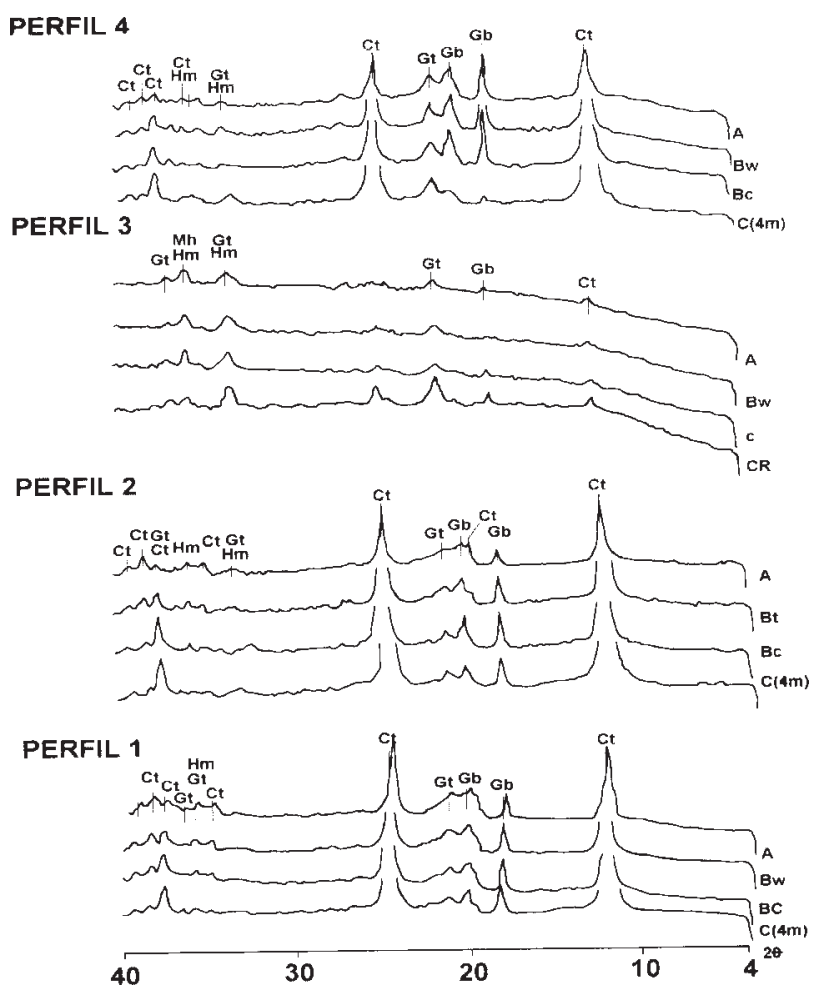

Figura 2. Difratogramas de raios $X$ da fração argi la dos perfis 1, 2, 3, e 4, sem pré-tratamento, com lâminas orientadas. Ct: caulinita, Gb: gibbsita, Gt: goethita, Hm: hematita, Mh: maghemita.

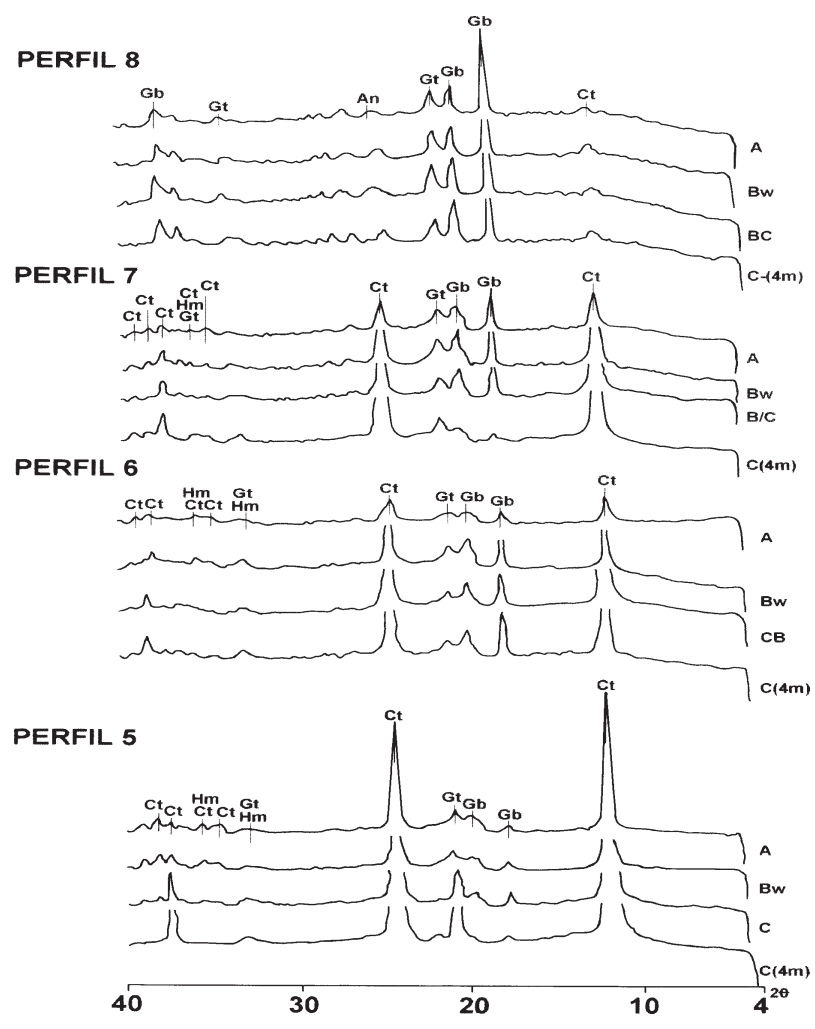

Figura 3. Difratogramas de raios $X$ da fração argila dos perfis $5,6,7$, e 8, sem pré-tratamento, com lâmi nas orientadas. Ct: caulinita, Gb: gibbsita, Gt: goethita, Hm: hematita, An: anatásio. 
Quadro 6. Resultados de ataque sulfúrico na TFSA de amostras dos solos em estudo

\begin{tabular}{|c|c|c|c|c|c|c|c|c|}
\hline Solo & Horizonte & $\mathrm{SiO}_{2}$ & $\mathrm{Al}_{2} \mathrm{O}_{3}$ & $\mathrm{Fe}_{2} \mathrm{O}_{3}$ & $\mathbf{P}_{2} \mathrm{O}_{5}$ & $\mathrm{TiO}_{2}$ & $\mathbf{K} \mathbf{i}^{(1)}$ & $\mathbf{K r}^{(2)}$ \\
\hline & & \multicolumn{7}{|c|}{$\mathrm{g} \mathrm{kg}^{-1} \longrightarrow$} \\
\hline 1 & $\begin{array}{l}\text { A } \\
\text { Bw } \\
\text { BC } \\
\text { C-4m }\end{array}$ & $\begin{array}{r}85,2 \\
118,6 \\
114,8 \\
164,6\end{array}$ & $\begin{array}{l}224,4 \\
265,2 \\
283,1 \\
260,1\end{array}$ & $\begin{array}{l}54,0 \\
56,0 \\
57,0 \\
34,0\end{array}$ & $\begin{array}{l}0,07 \\
0,08 \\
0,05 \\
0,01\end{array}$ & $\begin{array}{l}2,6 \\
1,9 \\
1,9 \\
1,4\end{array}$ & $\begin{array}{l}0,65 \\
0,76 \\
0,68 \\
1,07\end{array}$ & $\begin{array}{l}0,56 \\
0,67 \\
0,61 \\
0,99\end{array}$ \\
\hline 2 & $\begin{array}{l}\mathrm{A} \\
\mathrm{Bt} \\
\mathrm{BC} \\
\mathrm{C}-4 \mathrm{~m}\end{array}$ & $\begin{array}{r}134,4 \\
170,0 \\
95,2 \\
13,0\end{array}$ & $\begin{array}{l}204,0 \\
275,4 \\
201,5 \\
260,1\end{array}$ & $\begin{array}{l}53,0 \\
69,0 \\
72,0 \\
40,0\end{array}$ & $\begin{array}{l}0,07 \\
0,07 \\
0,07 \\
0,03\end{array}$ & $\begin{array}{l}2,5 \\
2,5 \\
1,8 \\
1,5\end{array}$ & $\begin{array}{l}1,12 \\
1,05 \\
0,80 \\
0,08\end{array}$ & $\begin{array}{l}0,96 \\
0,90 \\
0,65 \\
0,03\end{array}$ \\
\hline 3 & $\begin{array}{l}\text { A } \\
B w \\
C \\
C R\end{array}$ & $\begin{array}{l}2,4 \\
2,2 \\
3,4 \\
0,8\end{array}$ & $\begin{array}{r}89,3 \\
89,3 \\
102,0 \\
91,8\end{array}$ & $\begin{array}{l}590,0 \\
745,0 \\
612,0 \\
599,0\end{array}$ & $\begin{array}{l}- \\
- \\
-\end{array}$ & $\begin{array}{l}1,8 \\
2,4 \\
2,0 \\
1,7\end{array}$ & $\begin{array}{l}0,05 \\
0,04 \\
0,06 \\
0,01\end{array}$ & $\begin{array}{l}0,009 \\
0,007 \\
0,012 \\
0,003\end{array}$ \\
\hline 4 & $\begin{array}{l}\text { A } \\
\text { Bw } \\
\text { BC } \\
\text { C-4m }\end{array}$ & $\begin{array}{r}133,4 \\
66,0 \\
79,0 \\
1,6\end{array}$ & $\begin{array}{l}257,6 \\
290,7 \\
303,5 \\
237,2\end{array}$ & $\begin{array}{l}133,0 \\
147,0 \\
150,0 \\
146,0\end{array}$ & $\begin{array}{l}0,05 \\
0,08 \\
0,07 \\
0,02\end{array}$ & $\begin{array}{l}2,9 \\
4,8 \\
5,0 \\
1,2\end{array}$ & $\begin{array}{l}0,88 \\
0,38 \\
0,44 \\
0,01\end{array}$ & $\begin{array}{l}0,66 \\
0,29 \\
0,34 \\
0,008\end{array}$ \\
\hline 5 & $\begin{array}{l}\text { A } \\
\text { Bw } \\
\text { C } \\
\text { C-4m }\end{array}$ & $\begin{array}{l}168,5 \\
190,8 \\
199,6 \\
188,1\end{array}$ & $\begin{array}{l}150,5 \\
202,7 \\
221,9 \\
225,7\end{array}$ & $\begin{array}{l}76,0 \\
83,0 \\
76,0 \\
98,0\end{array}$ & $\begin{array}{l}0,02 \\
0,01 \\
0,01 \\
0,01\end{array}$ & $\begin{array}{l}2,4 \\
1,7 \\
3,9 \\
4,2\end{array}$ & $\begin{array}{l}1,90 \\
1,60 \\
1,53 \\
1,42\end{array}$ & $\begin{array}{l}1,44 \\
1,27 \\
1,26 \\
1,11\end{array}$ \\
\hline 6 & $\begin{array}{l}\text { A } \\
\text { Bw } \\
\text { CB } \\
C-4 m\end{array}$ & $\begin{array}{l}61,4 \\
79,4 \\
46,2\end{array}$ & $\begin{array}{l}191,3 \\
249,9 \\
252,5 \\
178,5\end{array}$ & $\begin{array}{r}89,0 \\
108,0 \\
124,0 \\
99,0\end{array}$ & $\begin{array}{l}0,06 \\
0,05 \\
0,06 \\
0,04\end{array}$ & $\begin{array}{l}2,7 \\
5,2 \\
4,0 \\
0,9\end{array}$ & $\begin{array}{l}0,42 \\
0,53 \\
0,44\end{array}$ & $\begin{array}{l}0,32 \\
0,41 \\
0,32\end{array}$ \\
\hline 7 & $\begin{array}{l}\text { A } \\
B w \\
B / C \\
C-4 m\end{array}$ & $\begin{array}{r}90,4 \\
92,2 \\
99,4 \\
164,6\end{array}$ & $\begin{array}{l}193,8 \\
267,8 \\
285,6 \\
119,9\end{array}$ & $\begin{array}{l}68,0 \\
85,0 \\
85,0 \\
69,0\end{array}$ & $\begin{array}{l}0,05 \\
0,04 \\
0,04 \\
0,05\end{array}$ & $\begin{array}{l}1,1 \\
3,2 \\
2,2 \\
0,8\end{array}$ & $\begin{array}{l}0,79 \\
0,59 \\
0,59 \\
2,33\end{array}$ & $\begin{array}{l}0,65 \\
0,49 \\
0,50 \\
1,71\end{array}$ \\
\hline 8 & $\begin{array}{l}\text { A } \\
\text { Bw } \\
\text { BC } \\
\text { C- } 4 m\end{array}$ & $\begin{array}{l}3,2 \\
1,6 \\
3,6 \\
2,2\end{array}$ & $\begin{array}{l}181,1 \\
260,1 \\
262,7 \\
357,0\end{array}$ & $\begin{array}{r}92,0 \\
117,0 \\
120,0 \\
142,0\end{array}$ & $\begin{array}{l}0,03 \\
0,03 \\
0,03 \\
0,02\end{array}$ & $\begin{array}{l}2,6 \\
2,1 \\
1,9 \\
3,3\end{array}$ & $\begin{array}{l}0,03 \\
0,01 \\
0,02 \\
0,01\end{array}$ & $\begin{array}{l}0,022 \\
0,008 \\
0,018 \\
0,008\end{array}$ \\
\hline
\end{tabular}

TFSA = terra fina seca ao ar.

$$
{ }^{(1)} \mathrm{Ki}=\frac{1,7 \% \mathrm{SiO}_{2}}{\% \mathrm{Al}_{2} \mathrm{O}_{3}}
$$$$
{ }^{(2)} \mathrm{Kr}=\frac{1,7 \% \mathrm{SiO}_{2}}{\% \mathrm{Al}_{2} \mathrm{O}_{3}+0,6375 \% \mathrm{Fe}_{2} \mathrm{O}_{3}}
$$

Pode-se inferir que a sustentabilidade desses sistemas de produção florestal, em relação ao potencial de reserva para potássio de médio a longo prazoé praticamente inexistentenos sol os em estudo (Quadro 3), presente apenas, embora com baixa magnitude, nos solos 2 e 5 na forma de micas e feldspatos. A presença desses minerais primários na fração areia (solos 2 e 5) contribui com a reserva potencial de formas não-trocáveis de $\mathrm{K}$ para esses solos (Quadro 8).

\section{Potencial de reserva para cálcio e magnésio}

Os sol os em estudo são pobres em minerais ricos em cálcio e magnésio (Quadro 1), conseqüentemente, os teores de cál cio e magnésio totais também o são (Quadro 9). As relações Ca-trocável/Ca-total e Mg-trocável/M g-total exprimem baixa capacidade de reposição desses nutrientes no solo (Quadro 9).
Teores de cál cio e magnésio em formas trocáveis (Quadro 9) são inferiores aos níveis críticos exigidos na implantação, 2,0 e $0,5 \mathrm{mmol}_{c} \mathrm{dm}^{-3}$, respectivamente, ena manutenção, correspondentes aos IMAs 10, 20, 30, 40 e 50 os níveis aríticos 3,0 e 0,7; 4,5 e 1,$0 ; 6,0$ e 1,$3 ; 6,0$ e 1,$6 ; 8,0$ e $1,9 \mathrm{mmol}_{\mathrm{c}} \mathrm{dm}^{-3}$, respectivamente, aos valores de $\mathrm{Ca}$ e $\mathrm{Mg}$, de acordo com Barros et al. (1990).

As relações de $\mathrm{Ca}: \mathrm{Mg}$, que se pressupõem razoáveis quando próximas de $3: 1$ ou $4: 1$, são inferiores, apesar de essa cultura nãoser tão exigente em cálcio e magnésio, o que condiz com sua alta tolerância ao alumínio (Neves et al., 1982).

Atenção especial deve ser dada à capacidade de suprimento de cálcio, uma vez que significativa proporção do cálcio absorvido pelas plantas de eucalipto é imobilizada na casca (Barros et al., 1990). Outro fato é que, além de os sol os estudados 
Quadro 7. Caracterização química de amostras dos solos estudados

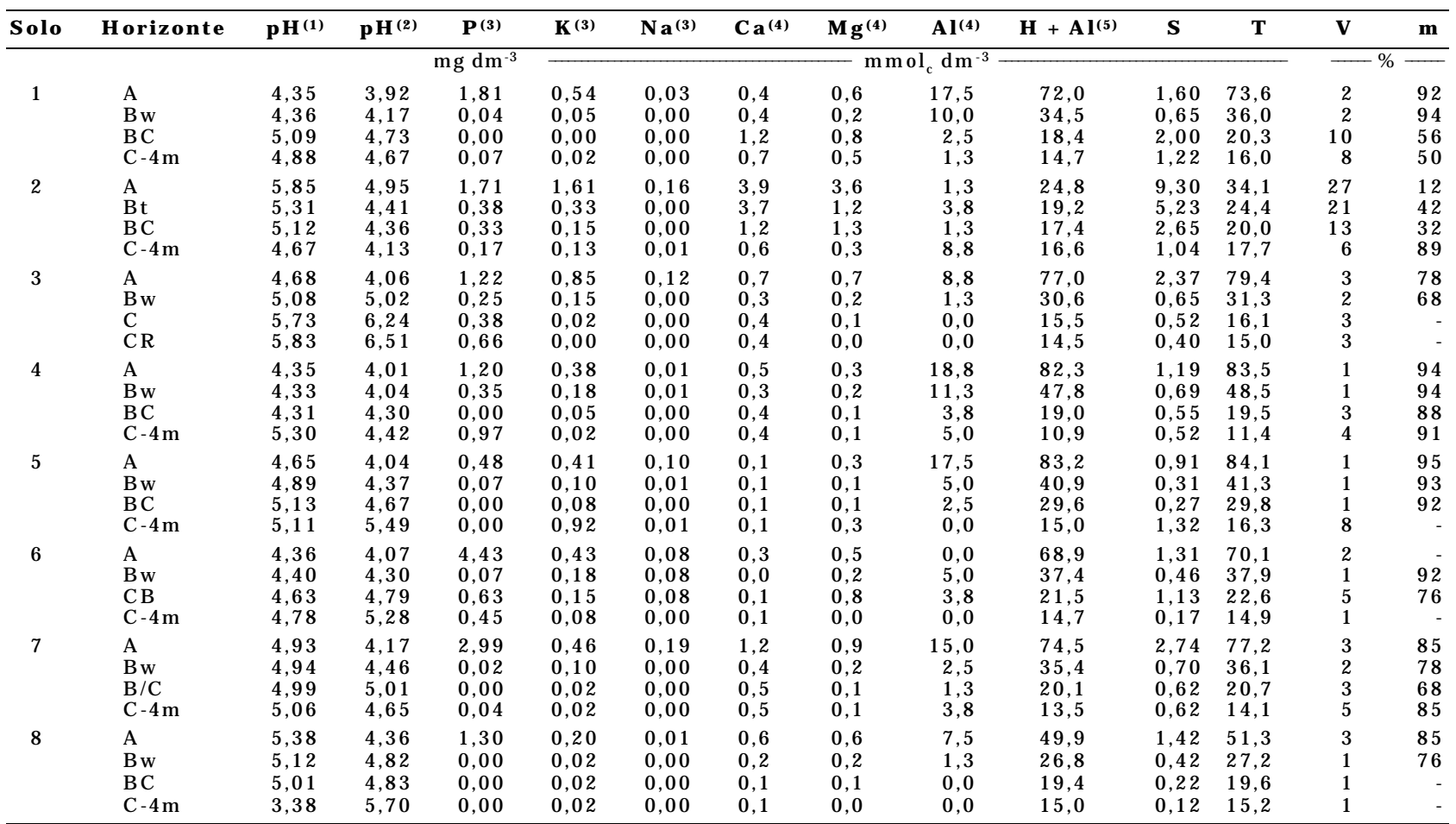

(1) $\mathrm{pH}_{\text {em H}} \mathrm{O}$. (2) $\mathrm{pH}$ em KCl $1 \mathrm{~mol} \mathrm{~L}^{-1}$. (3) Extrator Mehlich-1 $\left(\mathrm{HCl} 0,05 \mathrm{~mol} \mathrm{~L}^{-1}+\mathrm{H}_{2} \mathrm{SO}_{4} 0,0125 \mathrm{~mol} \mathrm{~L}^{-1}\right)$. (4) Extrator KCl $1 \mathrm{~mol} \mathrm{~L}^{-1}$.

(5) Método potenciométrico do SMP (RAIJ et al., 1987).

Quadro 8. Teores de potássio em formas trocáveis, totais e suas relações em amostras dos solos estudados

\begin{tabular}{|c|c|c|c|c|c|}
\hline Solo & Horizonte & K-trocável(1) & K-total(2) & $\begin{array}{c}\text { K-trocável } \\
\text { K-total }\end{array}$ & I MA $\mathbf{A}^{(3)}$ \\
\hline & \multicolumn{3}{|c|}{$\mathrm{mg} \mathrm{dm}^{-3}-$} & & $\mathrm{m}^{3} \mathrm{ha}^{-1} \mathrm{ano}^{-1}$ \\
\hline 1 & $\begin{array}{l}\text { A } \\
\text { B w } \\
\text { B C } \\
\text { C }-4 m\end{array}$ & $\begin{array}{r}21 \\
2 \\
0 \\
1\end{array}$ & $\begin{array}{l}156 \\
160 \\
150 \\
339\end{array}$ & $\begin{array}{l}0,13 \\
0,01 \\
0,00 \\
0,00\end{array}$ & 47 \\
\hline 2 & $\begin{array}{l}\mathrm{A} \\
\mathrm{Bt} \\
\mathrm{BC} \\
\mathrm{C}-4 \mathrm{~m}\end{array}$ & $\begin{array}{r}63 \\
12 \\
6 \\
5\end{array}$ & $\begin{array}{l}502 \\
554 \\
594 \\
747\end{array}$ & $\begin{array}{l}0,12 \\
0,02 \\
0,01 \\
0,01\end{array}$ & 53 \\
\hline 3 & $\begin{array}{l}\text { A } \\
\text { B w } \\
\text { C } \\
\text { C R }\end{array}$ & $\begin{array}{r}33 \\
6 \\
1 \\
0\end{array}$ & $\begin{array}{l}211 \\
237 \\
181 \\
120\end{array}$ & $\begin{array}{l}0,16 \\
0,02 \\
0,01 \\
0,00\end{array}$ & 39 \\
\hline 4 & $\begin{array}{l}\text { A } \\
\text { B w } \\
\text { B C } \\
\text { C }-4 m\end{array}$ & $\begin{array}{r}16 \\
4 \\
3 \\
17\end{array}$ & $\begin{array}{l}189 \\
160 \\
145 \\
194\end{array}$ & $\begin{array}{l}0,08 \\
0,02 \\
0,02 \\
0,09\end{array}$ & 51 \\
\hline 5 & $\begin{array}{l}\text { A } \\
\text { B w } \\
\text { C } \\
\text { C }-4 m\end{array}$ & $\begin{array}{r}15 \\
7 \\
2 \\
1\end{array}$ & $\begin{array}{l}431 \\
359 \\
306 \\
292\end{array}$ & $\begin{array}{l}0,03 \\
0,02 \\
0,01 \\
0,00\end{array}$ & 44 \\
\hline 6 & $\begin{array}{l}\text { A } \\
\text { B w } \\
\text { C B } \\
\text { C }-4 m\end{array}$ & $\begin{array}{r}17 \\
7 \\
6 \\
3\end{array}$ & $\begin{array}{l}194 \\
183 \\
167 \\
235\end{array}$ & $\begin{array}{l}0,09 \\
0,04 \\
0,04 \\
0,01\end{array}$ & 40 \\
\hline 7 & $\begin{array}{l}\text { A } \\
B w \\
B / C \\
C-4 m\end{array}$ & $\begin{array}{r}18 \\
4 \\
1 \\
1\end{array}$ & $\begin{array}{l}63 \\
95 \\
76 \\
76\end{array}$ & $\begin{array}{l}0,28 \\
0,04 \\
0,01 \\
0,01\end{array}$ & 49 \\
\hline 8 & $\begin{array}{l}\text { A } \\
\text { B w } \\
\text { B C } \\
\text { C }-4 m\end{array}$ & $\begin{array}{l}8 \\
1 \\
1 \\
1\end{array}$ & $\begin{array}{r}68 \\
70 \\
79 \\
100\end{array}$ & $\begin{array}{l}0,12 \\
0,01 \\
0,01 \\
0,01\end{array}$ & 45 \\
\hline
\end{tabular}

(1) Extrator Mehlich-1 $\left(\mathrm{HCl} 0,05\right.$ mol L-1 $\left.+\mathrm{H}_{2} \mathrm{SO}_{4} 0,0125 \mathrm{~mol} \mathrm{~L}^{-1}\right)$. (2) Extrator ácido fluorídrico, metodologia CENA (Centro de Energia Nuclear na Agricultura). (3) IMA (Incremento Médio Anual). 
Quadro 9. Teores de cálcio e magnésio em formas trocáveis, totais e suas relações em amostras dos solos estudados

\begin{tabular}{|c|c|c|c|c|c|c|c|c|c|c|}
\hline \multirow{2}{*}{ Solo } & \multirow{2}{*}{ Horizonte } & \multicolumn{3}{|c|}{ Formas trocáveis(1) } & \multicolumn{3}{|c|}{ Formas totais(2) } & \multirow{2}{*}{$\begin{array}{c}\text { Ca-trocável } \\
\text { Ca-total }\end{array}$} & \multirow{2}{*}{$\frac{\text { Mg-trocável }}{\text { Mg-total }}$} & \multirow{2}{*}{ IMA(3) } \\
\hline & & $\mathbf{C a}$ & Mg & $\mathrm{Ca} / \mathrm{Mg}$ & $\mathrm{Ca}$ & Mg & $\mathrm{Ca} / \mathrm{Mg}$ & & & \\
\hline & & \multicolumn{3}{|c|}{$-\mathrm{mmol}_{\mathrm{c}} \mathrm{dm}^{-3}{ }_{-}$} & \multicolumn{3}{|c|}{$-\mathrm{mmol}_{\mathrm{c}} \mathrm{dm}^{-3}$} & & & $\mathrm{~m}^{3} \mathrm{ha}^{-1} \mathrm{ano}^{-1}$ \\
\hline 1 & $\begin{array}{l}\text { A } \\
\text { B w } \\
\text { BC } \\
\text { C }-4 m\end{array}$ & $\begin{array}{l}0,4 \\
0,4 \\
1,2 \\
0,7\end{array}$ & $\begin{array}{l}0,6 \\
0,2 \\
0,8 \\
0,5\end{array}$ & $\begin{array}{l}0,66 \\
2,00 \\
1,50 \\
1,40\end{array}$ & $\begin{array}{l}0,6 \\
0,6 \\
0,6 \\
0,6\end{array}$ & $\begin{array}{l}1,0 \\
1,0 \\
1,0 \\
1,0\end{array}$ & $\begin{array}{l}0,60 \\
0,60 \\
0,60 \\
0,60\end{array}$ & $\begin{array}{l}0,66 \\
0,66 \\
2,00 \\
1,16\end{array}$ & $\begin{array}{l}0,60 \\
0,20 \\
0,80 \\
0,50\end{array}$ & 47 \\
\hline 2 & $\begin{array}{l}\text { A } \\
\text { Bt } \\
\text { BC } \\
\text { C-4m }\end{array}$ & $\begin{array}{l}3,9 \\
3,7 \\
1,2 \\
0,6\end{array}$ & $\begin{array}{l}3,6 \\
1,2 \\
1,3 \\
0,3\end{array}$ & $\begin{array}{l}1,08 \\
3,08 \\
0,92 \\
2,00\end{array}$ & $\begin{array}{l}4,8 \\
3,0 \\
0,8 \\
0,7\end{array}$ & $\begin{array}{l}8,0 \\
2,2 \\
1,0 \\
1,8\end{array}$ & $\begin{array}{l}0,60 \\
1,36 \\
0,80 \\
0,39\end{array}$ & $\begin{array}{l}0,81 \\
1,23 \\
1,50 \\
0,85\end{array}$ & $\begin{array}{l}0,45 \\
0,54 \\
1,30 \\
0,16\end{array}$ & 53 \\
\hline 3 & $\begin{array}{l}\text { A } \\
B w \\
C \\
C R\end{array}$ & $\begin{array}{l}0,7 \\
0,3 \\
0,4 \\
0,4\end{array}$ & $\begin{array}{l}0,7 \\
0,2 \\
0,1 \\
0,0\end{array}$ & $\begin{array}{l}1,00 \\
1,50 \\
4,00 \\
0,00\end{array}$ & $\begin{array}{l}1,4 \\
0,6 \\
0,6 \\
0,6\end{array}$ & $\begin{array}{l}1,0 \\
4,0 \\
1,0 \\
1,0\end{array}$ & $\begin{array}{l}1,40 \\
0,15 \\
0,60 \\
0,60\end{array}$ & $\begin{array}{l}0,50 \\
0,50 \\
0,66 \\
0,66\end{array}$ & $\begin{array}{l}0,70 \\
0,05 \\
0,10 \\
0,00\end{array}$ & 39 \\
\hline 4 & $\begin{array}{l}\text { A } \\
\text { B w } \\
\text { BC } \\
\text { C }-4 m\end{array}$ & $\begin{array}{l}0,5 \\
0,3 \\
0,4 \\
0,4\end{array}$ & $\begin{array}{l}0,3 \\
0,2 \\
0,1 \\
0,1\end{array}$ & $\begin{array}{l}1,66 \\
1,50 \\
4,00 \\
4,00\end{array}$ & $\begin{array}{l}4,2 \\
1,8 \\
1,9 \\
2,6\end{array}$ & $\begin{array}{l}1,0 \\
1,0 \\
1,0 \\
1,0\end{array}$ & $\begin{array}{l}4,20 \\
1,80 \\
1,90 \\
2,60\end{array}$ & $\begin{array}{l}0,12 \\
0,16 \\
0,21 \\
0,15\end{array}$ & $\begin{array}{l}0,30 \\
0,20 \\
0,10 \\
0,10\end{array}$ & 51 \\
\hline 5 & $\begin{array}{l}\text { A } \\
\text { B w } \\
\text { C } \\
\text { C }-4 m\end{array}$ & $\begin{array}{l}0,1 \\
0,1 \\
0,1 \\
0,1\end{array}$ & $\begin{array}{l}0,3 \\
0,1 \\
0,1 \\
0,3\end{array}$ & $\begin{array}{l}0,33 \\
1,00 \\
1,00 \\
0,33\end{array}$ & $\begin{array}{l}1,3 \\
0,6 \\
0,6 \\
0,6\end{array}$ & $\begin{array}{l}1,0 \\
1,0 \\
1,0 \\
1,0\end{array}$ & $\begin{array}{l}1,30 \\
0,60 \\
0,60 \\
0,60\end{array}$ & $\begin{array}{l}0,08 \\
0,16 \\
0,16 \\
0,16\end{array}$ & $\begin{array}{l}0,30 \\
0,10 \\
0,10 \\
0,30\end{array}$ & 44 \\
\hline 6 & $\begin{array}{l}\text { A } \\
\text { B w } \\
\text { CB } \\
C-4 m\end{array}$ & $\begin{array}{l}0,3 \\
0,0 \\
0,1 \\
0,1\end{array}$ & $\begin{array}{l}0,5 \\
0,2 \\
0,8 \\
0,0\end{array}$ & $\begin{array}{l}0,60 \\
0,00 \\
0,12 \\
0,00\end{array}$ & $\begin{array}{l}0,6 \\
0,6 \\
0,6 \\
0,6\end{array}$ & $\begin{array}{l}1,0 \\
1,0 \\
1,0 \\
1,0\end{array}$ & $\begin{array}{l}0,60 \\
0,60 \\
0,60 \\
0,60\end{array}$ & $\begin{array}{l}0,50 \\
0,00 \\
0,16 \\
0,16\end{array}$ & $\begin{array}{l}0,50 \\
0,20 \\
0,80 \\
0,00\end{array}$ & 40 \\
\hline 7 & $\begin{array}{l}\mathrm{A} \\
\mathrm{B} w \\
\mathrm{~B} / \mathrm{C} \\
\mathrm{C}-4 \mathrm{~m}\end{array}$ & $\begin{array}{l}1,2 \\
0,4 \\
0,5 \\
0,5\end{array}$ & $\begin{array}{l}0,9 \\
0,2 \\
0,1 \\
0,1\end{array}$ & $\begin{array}{l}1,30 \\
2,00 \\
5,00 \\
5,00\end{array}$ & $\begin{array}{l}0,6 \\
0,6 \\
0,6 \\
0,6\end{array}$ & $\begin{array}{l}1,0 \\
1,0 \\
1,0 \\
1,0\end{array}$ & $\begin{array}{l}0,60 \\
0,60 \\
0,60 \\
0,60\end{array}$ & $\begin{array}{l}2,00 \\
0,66 \\
0,83 \\
0,83\end{array}$ & $\begin{array}{l}0,90 \\
0,20 \\
0,10 \\
0,10\end{array}$ & 49 \\
\hline 8 & $\begin{array}{l}\text { A } \\
\text { B w } \\
\text { B C } \\
\text { C }-4 m\end{array}$ & $\begin{array}{l}0,6 \\
0,2 \\
0,1 \\
0,1\end{array}$ & $\begin{array}{l}0,6 \\
0,2 \\
0,1 \\
0,0\end{array}$ & $\begin{array}{l}1,00 \\
1,00 \\
1,00 \\
0,00\end{array}$ & $\begin{array}{l}0,6 \\
0,6 \\
0,6 \\
0,6\end{array}$ & $\begin{array}{l}1,0 \\
1,0 \\
1,0 \\
1,0\end{array}$ & $\begin{array}{l}0,60 \\
0,60 \\
0,60 \\
0,60\end{array}$ & $\begin{array}{l}1,00 \\
0,33 \\
0,16 \\
0,16\end{array}$ & $\begin{array}{l}0,60 \\
0,20 \\
0,10 \\
0,00\end{array}$ & 45 \\
\hline
\end{tabular}

(1) Extrator Mehlich-1 ( $\mathrm{HCl} 0,05$ mol L-1 $+\mathrm{H}_{2} \mathrm{SO}_{4} 0,0125$ mol L $\left.{ }^{-1}\right)$. ${ }^{(2)}$ Extrator ácido fluorídrico, metodologia CENA (Centro de Energia Nuclear na Agricultura). (3) IMA (incremento médio anual).

apresentarem baixa sustentabilidade de suprimento de cálcio, os métodos de exploração florestal atual mente utilizados noBrasil retiram da área toda a porção utilizável do tronco (casca + lenho), colaborando com o aumento na exportação de cálcio.

\section{CONCLUSÕES}

1. Os solos estudados apresentam avançado estádio de intemperização, com a concentração relativa de argilominerais 1:1 e óxidos de ferro e alumínio, representados por caulinita, gibbsita, hematita, goethita e maghemita.

2. Mineralogi camente, os sol os foram classificados como: caulinítico-não-sesquioxídicos (2 e 5); caulinítico-sesquioxídico (1), gibbsítico-sesquioxídicos (4, 6 e 7), hematítico (3), e gibbsítico (8).
3. A reserva mineral de médioa longo prazo para potássio é praticamente inexistente, fazendo-se presente, embora com baixa magnitude, nos solos 2 e 5, na forma de micas e feldspatos.

4. As relações Ca-trocável/Ca-total eMg-trocável/ Mg-total exprimem baixa capacidade de reposição desses nutrientes nos solos.

5. A baixa capacidade desses solos em repor nutrientes para a cultura de eucalipto leva à necessidade de adicioná-los, para se atingir a sustentabilidade desses sítios florestais.

\section{LITERATURA CITADA}

BARROS, N.F.; NOVAIS, R.F. \& NEVES, J.C.L. Fertilização e correção do solo para o plantio de eucalipto. In: BARROS, N. F. \& NOVAIS, R.F., eds. Relação solo-eucalipto. Viçosa, Folha de Viçosa, 1990. p. 127-186. 
BOYER, J.L. Dinâmica dos elementos químicos e fertilidade dos solos. Salvador, Instituto de Geociências da UFBA, 1985. 311p.

BRASIL. Ministério da Agricultura. Equipe de pedologia e fertilidade do solo. Levantamento exploratório dos sol os da região sob influência do Cia Vale do Rio Doce. Rio deJ aneiro, 1970. 154 p. (Bol etim Técnico, 13)

BRASIL. Ministério das Minas e Energia, Secretaria Geral. PROJ ETO RADAMBRASIL. Levantamento de Recursos Naturais, Folhas SF. 23/24 Rio de J aneiro/Vitória. Rio de J aneiro, 1983. v.32. 775p.

COSTA, J .B. Caracterização e constituição do sol o. 2. ed. Lisboa, Fundação Calouste Gulbenkian, 1979. 527p.

CURI, N. Lithosequence and toposequence of Oxisols from Goiás and Minas Gerais State, Brazil. West Lafayette, Purdue University, 1983. 158 p. (Tese de Doutorado)

EMPRESA BRASILEIRA DE PESQUISA AGROPECUÁRIA EMBRAPA. Serviço Nacional de Levantamento e Conservação de Solos. Manual de métodos de análise de solo. Rio de J aneiro, 1979. não paginado.

FABRES, A.S.; COUTO, C.; CARMO, D.N.; BARBOSA, F.L.; TEIXEIRA, J .L.; NEVES, J.C.L.; COSTA, L.M.; CAPITANI, L.R.; BARROS, N.F.; LEAL, P.G.L.; NOVAIS, R.F.; CASTRO, A.P.A. \& FREITAS, I.F. Produtividade e exportação de nutrientes em eucaliptos e identificação de sítios visando manejo de solo e o manejo florestal em área da CENIBRA. Viçosa, Convênio SIF/CNB-F. 1987. 142p.

FONSECA, S. Propriedades físicas, químicas e microbiológicas de um Latossolo Vermel ho-Amarelo sob eucalipto, mata natural e pastagem. Viçosa, U niversidade Federal deViçosa, 1984. 78p. (Tese de Mestrado)

J ACKSON, M.L. Soil chemical analysis-advanced course. 2. ed. Madison, M.L. J ackson, 1979. 895p.

LEMOS, R.C. \& SANTOS, R.D. Manual de descrição e coleta de solo no campo. Campinas, SBCS/SNLCS, 1982. 45p.

LIMA, W.P. Solo e eucalipto. In: LI MA, W.P., ed. I mpacto ambiental do eucalipto. São Paulo, EDUSP, 1993. p.139-168.

MELO, V.F.; COSTA, L.M.; BARROS, N.F.; FONTES, M.P.F. \& NOVAIS, R.F. Reserva mineral e caracterização mineralógica deal guns sol os do Rio Grande do Sul. R. Bras. Ci. Solo, 19:159-164, 1995.
NEVES,J .C.L.; BARROS, N.F.; NOVAIS, R.F. \& ANJ OS, J .L. Efeito do alumínio em amostras de dois Latossolos sob cerrado sobre crescimento e a absorção de nutrientes de mudas de Eucalyptus grandis. R. Árv., 6:17-28, 1982.

RAIJ , B. van; QUAGGIO, J . A. ; CANTARELLA, H. ; FERREIRA, M. E. ; LOPES, A. S. \& BATAGLIA, O. C. Análise química do sol o para fins defertilidade. Campinas, Fundação Cargill, 1987. $170 \mathrm{p}$.

RESENDE, M. Mineralogy, chemistry, morphology and geomorphology of some soils of the Central Plateau of Brazil. West Lafayette, PurdueUniversity, 1976. 237 p. (Tese de Doutorado)

RESENDE, M.; SANTANA, D.P.; FRANZMEIER, D.P. \& COEY, J.M.D. Magnetic properties of Brazilian Oxisols. In: INTERNATIONAL SOIL CLASSIFICATION WORKSHOP, 8., Rio deJ aneiro, 1986. Proceedings. Rio deJ aneiro, SMSS/ EMBRAPA/UPR, 1986. Part 1. p.78-108.

RESENDE, M.; BAHIA FILHO, A.F.C. \& BRAGA, J.M. Mineralogia da argila de Latossolos estimada por alocação a partir do teor total de óxidos do ataque sulfúrico. R. Bras. Ci. Solo, 11:17-23, 1987.

RESENDE，M.; SANTANA，D.P. \& REZENDE， S.B. Susceptibilidade magnética em $L$ atossol os do Sudestee Sul do Brasil. In: REUNIÃO DE CLASSIFICAÇÃO, CORRELAÇÃO DE SOLOS E INTERPRETAÇÃO DE APTIDÃO AGRí COLA, 3., Rio de J aneiro, 1988. Anais. Rio de J aneiro, EMBRAPA-SNLCS, 1988. p.233-258.

RESENDE, M. \& SANTANA, D.P. Uso das relações Ki e Kr na estimativa da mineralogia para classificação dos $L$ atossolos. In: REUNIÃO DE CLASSIFICAÇÃO, CORRELAÇÃO DE SOLOS E INTERPRETAÇÃO DE APTIDÃO AGRÍCOLA, 3., Rio de J aneiro, 1988. Anais. Rio de J aneiro, EMBRAPASNLCS, 1988. p.225-232.

SANTOS, P.S. Indentificação mineralógica de argilas-1. Análise química e capacidade de troca de cátions. In: SANTOS, P.S., ed. Tecnol ogia de argilas. São Paulo, Edgard Blücher, 1982. p.210-241.

SANTOS,A.R. Caracterização mineralógica e avaliação da reserva mineral de alguns nutrientes, em solos sob eucalipto, da região do Vale do Rio Doce. Viçosa, Universidade Federal de Viçosa, 1993. 97p. (Tese de Mestrado)

VETTORI, L. Métodos de análise de solo. Brasília, Ministério da Agricultura, 1969. 24p. (Boletim técnico, 7)

WHITTIG, L. D. \& ALLARDICE, W. R. X - ray diffraction techiques. In: KLUTE, A., ed. Methods of soil analysis. Madison, American Society of Agronomy, 1986. Part 1. p.331362. 